\title{
Functional maturation of the epididymis in the rat
}

\author{
B. S. Setty and Q. Jehan \\ Division of Endocrinology, Central Drug Research Institute, Lucknow, India
}

\begin{abstract}
Summary. Weight, histological and biochemical changes in the rat epididymis were investigated during prepubertal, pubertal and postpubertal periods. The phase of most rapid growth of the epididymis commenced at 21 days and extended to 60 days of age; this period corresponded closely to the onset of androgen production at 3 weeks and stabilization of the Leydig cell number at 60 days. Histological differentiation in the caput epididymidis started before sperm entry and was complete in the cauda only several days after the spermatozoa had appeared. The presence of appreciable quantities of glycerylphosphorylcholine (GPC) and sialic acid in the epididymis of 21-day-old rats suggests inherent secretory ability of the epididymal epithelium. The concentrations of GPC, sialic acid, phospholipids and glycogen in the epididymis gradually increased with age, but each came under the influence of androgen at a different age. There was no evidence to suggest that the presence of spermatozoa has a stimulatory effect on the epididymis. Maximal secretory activity of the epididymis became established only by 90 days of age.
\end{abstract}

\section{Introduction}

Although histological and biochemical changes that occur during testicular maturation are well documented, little is known about the preparatory changes that take place in the epididymis in the prepubertal rat. The epididymis, like the accessory sex glands, is an androgen-dependent organ (Bishop, 1961), and other testicular products, e.g. rete testis fluid and/or spermatozoa, may also affect epididymal physiology (Elliot, 1965; Waites \& Setchell, 1969). Reid (1959) has studied the histogenesis of the rat epididymis from birth to puberty and Brooks (1976) has examined the changes throughout the whole excurrent duct system. We have investigated the functional maturation of the epididymis while critical events are occurring in the gametogenic and endocrine compartments of the testis. The present study covers the period from the time the epididymis first becomes influenced by androgens to that when the histological differentiation in all epididymal regions is complete. Epididymal maturation at different ages was also compared with that of the accessory sex glands.

\section{Materials and Methods}

Colony-bred male rats of known birth date were killed at 21, 35 and 42 days (prepubertal) and 60,90 and 120 days (pubertal) of age. To examine the response of the epididymis to exogenous androgen, prepubertal animals were treated i.m. with 100 or $150 \mu \mathrm{g}$ testosterone propionate/day from the 14th or 28 th day of age, respectively, daily for 7 days (Table 1). All the rats were reared under uniform husbandry conditions in air-conditioned $\left(24 \pm 1^{\circ} \mathrm{C}\right)$ quarters.

At autopsy the testes, caput and cauda portions of the epididymis, seminal vesicles, ventral prostate and coagulating gland were excised and weighed. The testes and epididymal segments were fixed in Bouin's fluid and the sections were stained with haematoxylin and eosin. Levels of total protein (Umbreit, Burris \& Stauffer, 1959), sialic acid (Aminoff, 1961), glycogen (Montgomery, 1957), phospholipid (Hawk, Oser \& Summerson, 1957) and glycerylphosphorylcholine (GPC) (White, 1959) were measured in epididymal tissue. Alkaline phosphatase activity in the ventral prostate and fructose concentration of the coagulating gland were taken as indices of secretory 
activity of the accessory sex glands. The activity of alkaline phosphatase was measured according to the procedure of Hawk et al. (1957) using sodium $\beta$-glycerophosphate as substrate and is expressed as mg phosphorus released $/ \mathrm{h}$ at $37^{\circ} \mathrm{C}$. The technique of Mann (1946) was used to determine fructose concentration. For the 21-day-old group, tissues from 3 or 4 animals were pooled for each estimation and each constituent was determined from 6-8 such pools. For the other groups, each consisting of 6-8 rats, both epididymides of each animal were combined for the estimations.

The results were assessed by Student's $t$ test and a level of $5 \%$ was taken to be significant.

\section{Results}

\section{Weight changes}

A significant increase in weight of the testis, epididymis and accessory sex glands was found at all the ages studied (Table 1); maximum increase ( $200 \%$ ) occurred for the testis between 21 and 35 days, and for the epididymis between 35 and 60 days. Treatment with testosterone propionate for 7 days at 14 and 28 days of age caused an increase in the weight of the caput and cauda epididymidis and in the weight and secretory activity of the accessory genital organs.

\section{Histological changes}

Spermatogenesis had reached the stage of pachytene spermatocytes by 21 days, through the early steps of spermatid development by 35 days and was complete by 60 days of age. In the interstitium there was a preponderance of fibroblast-like cells at 21 days but only a few fully developed Leydig cells. There was a gradual increase in the number of fully differentiated Leydig cells with age, reaching a maximum at 60 days.

In 21-day-old rats the tubular diameter of the epididymis was narrow and the lumen was lined by cuboidal or columnar cells which were arranged in one or two layers. Stereocilia had appeared in some tubules of the caput but none was present in the cauda epididymidis. By 35 days there was an increase in the tubular diameter and the initial segment of the caput epididymidis showed distinct adult features although the epithelial cell height was relatively low. In the distal caput region a stratified epithelium was seen only in a few areas and the lumen contained a few spermatids. In the cauda region the epithelium was $2-4$ cells thick and the cells were of the columnar type. In 60-day-old rats the caput epididymidis showed all the adult features, including spermatozoa, but it was not until 90 days that the cauda had differentiated into the adult type and so-called light or clear cells could be seen in the epithelium. In the proximal cauda epididymidis the size of the tubules was greater than that in the caput and the epithelial cells were low and columnar, while in the distal cauda the tubular diameter was maximal and the lumen was lined by cuboidal epithelium.

Treatment with testosterone propionate resulted in a marked increase in tubular size and there was evidence of hypertrophy and hyperplasia. The number of mitotic figures increased by about $65 \%$ at 21 days and by $100 \%$ at 35 days compared with the respective untreated controls (mitotic figures/ 100 tubules in the controls at 21 days: caput 12 , cauda 6 ; at 35 days: caput 4 , cauda 3 ). Androgen treatment failed to induce differentiation of the epithelium in the initial segment at 21 days but hastened the appearance of stereocilia in the caput and cauda regions.

\section{Biochemical changes}

There was a significant increase in sialic acid concentration in the caput epididymidis up to 42 days followed by a decline at 60 days and the level remained unaltered during puberty. In contrast, there was a gradual but insignificant rise with age in the cauda region. In all the age groups (excepting 42 days) sialic acid concentration was higher in the cauda epididymidis $(P<0.01)$. A marked increase in glycogen level was seen up to 90 days in both the segments of the epididymis.

The first significant rise in phospholipid content was seen at 60 days and the level was maintained until 120 days. At 35 days and later, the cauda epididymidis contained higher concentrations of 


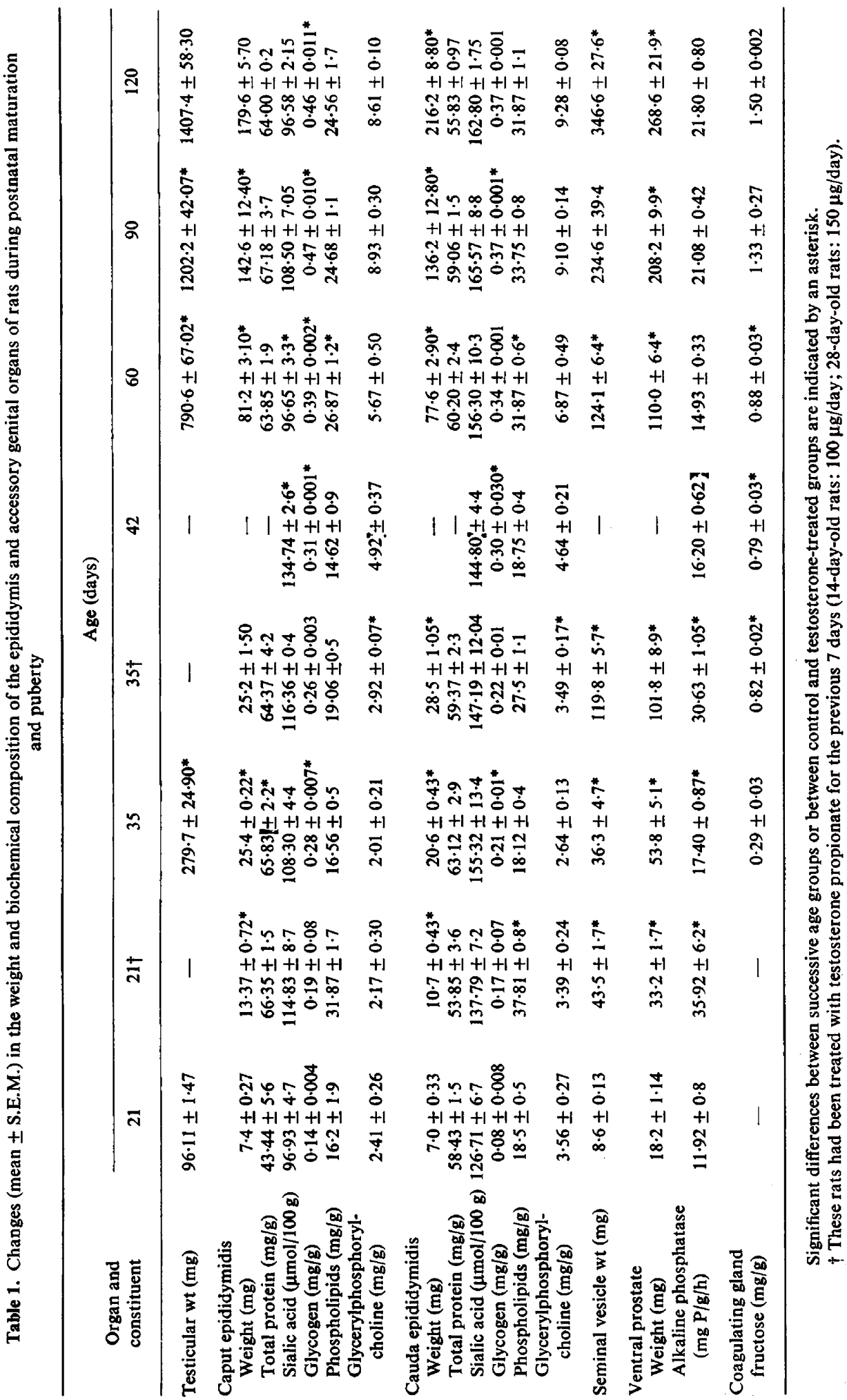


phospholipids. The concentration of GPC rose slightly at 35 days; a marked rise was observed at 42 days but peak values were attained only by 90 days. In the prepubertal rats GPC concentration was relatively higher in the cauda epididymidis $(P<0.05)$ but with age the difference between the two segments became negligible.

Treatment with testosterone propionate (Table 1) resulted in a significant rise in the phospholipid and GPC concentrations of the epididymis but it failed to alter the levels of glycogen and sialic acid. There was a marked increase in the secretory activity of the accessory sex glands in immature rats following androgen therapy.

\section{Discussion}

The present study shows that the functional maturation of the epididymis and accessory sex glands of prepubertal rats occur together. The first phase of rapid growth of the epididymis (up to 60 days) corresponds closely to the period between the onset of androgen production and the attainment of high circulating levels of testosterone and dihydrotestosterone (Knorr, Vanha-Perttula \& Lipsett, 1970; Gupta, Zarzycki \& Rager, 1975). The increase in accessory organ weight up to 60 days was equivalent to those of the epididymis and testes and thereafter the growth of the accessory sex glands exceeded that of the epididymis. The weight changes in the accessory organs and epididymis up to 60 days of age probably reflect true tissue growth, whereas in sexually mature rats they reflect both the tissue growth and an increase in their secretory products. This supposition is substantiated by the present observations on testosterone-treated prepubertal rats and those on adult castrated rats (Rajalakshmi \& Prasad, 1968; Brooks, Hamilton \& Mallek, 1974).

The Leydig cells are functional in 21-day-old rats (Knorr et al., 1970; Podesta \& Rivarola, 1974) although the epididymis is still histologically undifferentiated. At this age, however, dihydrotestosterone and cytoplasmic receptors appear (Calandra, Podesta, Rivarola \& Blaquier, 1974), together with increased levels of androgen-binding protein (ABP) (Hansson et al., 1974), in the caput region, suggesting that the epididymis is already under the influence of androgens. The number of fully differentiated Leydig cells increases by 35 days when plasma concentrations of testosterone and dihydrotestosterone are reported to be rising (Gupta et al., 1975). Histological differentiation was at an advanced stage in the caput region while the cauda epididymidis continued to show infantile features. The presence of spermatids in the epididymal ducts at this age suggests that testicular fluid, possibly containing androgen (Cooper \& Waites, 1974), was entering the epididymis in significant quantities (see Setchell, 1970), thus facilitating early differentiation of the caput region. The development of stereocilia appears to be androgen-mediated since their appearance in prepubertal rats could be hastened by exogenous testosterone.

Spermatozoa were present in the epididymal tubules of 60-day-old rats. Peak levels of ABP in the caput are seen around this age (Hansson et al., 1974) and the concentration of dihydrotestosterone within the epididymal tissue is about 5-fold more than at 35 days (Calandra et al., 1974). These findings suggest that the rat attains puberty by 60 days of age, both in terms of gametogenic and endocrine activities. The delay of histological differentiation of the cauda epididymidis into the adult type until 90 days could be due to a low receptor concentration in the cauda epididymidis of growing animals or to a higher requirement of androgen by this region (Gupta, Rajalakshmi \& Prasad, 1974).

The presence of appreciable quantities of GPC and sialic acid in the epididymis of 3-week-old rats, before its histological differentiation and testicular androgen production, suggests inherent secretory ability of the epithelium. At this age the epididymis and the accessory organs have the capacity to respond to androgen stimulation. It is, however, only in the 6th post-natal week that androgen-induced stimulation of epididymal secretory activity becomes evident (Hall \& Gomes, 1973; Gupta et al., 1975), and this is well in advance of sperm entry.

A second rise in GPC level between 60-90 days is possibly due to a further increase in the concentration of androgens in the circulation (Ghanadian, Lewis \& Chisholm, 1975) and in the epididymal tissue itself (Calandra et al., 1974). The significant increase in epididymal GPC concentration in the androgen-treated prepubertal rats supports this view, because spermatozoa do not participate in the 
accumulation of GPC in the epididymis (Dawson \& Rowlands, 1959; Brooks et al., 1974). Until 60 days of age the cauda epididymidis contained relatively higher concentrations of GPC. Although the caput epididymidis is reported to be more active in GPC synthesis (Dawson \& Rowlands, 1959), a higher concentration is to be expected in the cauda if GPC is even partly responsible for maintaining osmotic pressure of fluid in this region (Riar, Setty \& Kar, 1973).

A rise in the sialic acid level in the caput epididymidis until Day 42 followed by a significant fall at 60 days suggests a dilution imposed by testicular fluid, and ligation of the efferent ducts before the onset of puberty prevents this fall in sialic acid (Rajalakshmi \& Prasad, 1969). Since nearly $80 \%$ of the testicular fluid is resorbed in the proximal epididymis (Howards, Johnson \& Jessee, 1975), no dilution in the sialic acid level is to be expected in the cauda epididymidis at puberty; at all the ages examined the cauda generally contained higher sialic acid concentrations. Previous investigators have reported that the sialic acid concentration in the epididymis is androgen-dependent (Peyre \& Laporte, 1966; Rajalakshmi \& Prasad, 1968). The present study, however, has shown that androgen does not influence the sialic acid level in the epididymis of prepubertal rats: its continued rise in the epididymis even before sperm entry indicates that this constituent is locally synthesized. Brooks (1976) has also reached a similar conclusion.

Our findings on the amounts of protein and glycogen in the epididymis of maturing rats are comparable to those of Brooks (1976). Glycogen in the epididymal epithelium has been considered as an energy reserve (Brooks, 1976), and as a source of the glucose-6-phosphate needed for pentose phosphate activity in this organ (Sholl \& Leathem, 1973). The rise in phospholipid concentration at 60 days of age does not seem to be due to sperm entry because efferent duct ligation is reported not to alter epididymal phospholipid level (Turner \& Johnson, 1971); the elevated androgen concentrations in the mature rat are probably the stimulating factor.

This investigation was supported by a grant from the Ministry of Health and Family Planning, Government of India. We thank Dr Nitya Nand, Director for his interest in the study, Professor G. M. H. Waites for his hlepful suggestions in the preparation of the manuscript and Mrs S. F. Dalton for typing it.

\section{References}

Aminoff, D. (1961) Methods for the quantitative estimation of $N$-acetylneuraminic acid and their application to hydrolysates of sialomucoids. Biochem.J.81, 384-392.

Bishop, D.W. (1961) Biology of spermatozoa. In Sex and Internal Secretions, 3rd edn, Vol. II, pp. 707-796. Ed. W. C. Young. Williams and Wilkins, Baltimore.

Brooks, D.E. (1976) Changes in the composition of the excurrent duct system of the rat testis during postnatal development. J. Reprod. Fert. 46, 31-38.

Brooks, D.E., Hamilton, D.W. \& Mallek, A.H. (1974) Carnitine and glycerylphosphorylcholine in the reproductive tract of the male rat. J. Reprod. Fert. 36, 141-160.

Calandra, R.S., Podesta, E.J., Rivarola, M.A. \& Blaquier, J.A. (1974) Tissue androgens and androphilic proteins in rat epididymis during sexual development. Steroids 24, 507-518.

COOPER, T.G. \& WAITES, G.M.H. (1974) Testosterone in rete testis fluid and blood of rams and rats.J. Endocr. 62, 619-629.

DAWSON, R.M.C. \& Rowlands, I.W. (1959) Glycerylphosphorylcholine in male reproductive organs of rats and guinea pigs. Q.Jl exp. Physiol. 44, 26-34.
Elliot, P.R. (1965) Effect of efferentiectomy and orchidectomy on the metabolism of the epididymis of the mouse. J. cell. comp. Physiol. 66, 293-302.

Ghanadian, R., Lewis, J.G. \& Chisholm, G.D. (1975) Serum testosterone and dihydrotestosterone changes with age in rat. Steroids 25, 753-762.

GuPTA, D., ZARZYCKI, J. \& RAGer, K. (1975) Plasma testosterone and dihydrotestosterone in male rats during sexual maturation and following orchidectomy and experimental bilateral cryptorchidism. Steroids 25, 33-42.

Gupta, G., Rajalakshmi, M. \& Prasad, M.R.N. (1974) Regional differences in androgen thresholds of the epididymis of the castrated rat. Steroids 24, 575-586.

Hall, R.W. \& Gomes, W.R. (1973) Testosterone levels in the serum and testes of growing rats following prenatal exposure to Busulphan. J. Reprod. Fert. 35, 131-134.

Hansson, V., Trygstad, O., French, F.S., Mclean, W.S., SMTh, A.A., Tindall, D.J., Weddington, S.C., Petrusz, P., Nayfeh, S.N. \& Ritzén, E.M. (1974) Androgen transport and receptor mechanisms in testis and epididymis. Nature, Lond. 250, 387-391. 
Hawk, P.B., Oser, B.L. \& Summerson, W.H. (1957) Practical Physiological Chemistry. McGraw Hill, New York.

Howards, S.S., Johnson, A. \& Jessee, S. (1975) Micropuncture and microanalytic studies of the rat testis and epididymis. Fert. Steril. 26, 13-19.

KNORR, D.W., VANHA-PerTtula, T. \& LipsetT, M.B. (1970) Structure and function of rat testis through pubescence. Endocrinology 86, 1298-1304.

MANN, T. (1946) Studies on the metabolism of semen. 3. Fructose as a normal constituent of seminal plasma. Site of formation and function of fructose in semen. Biochem.J.40, 481-491.

MONTGOMERY, R. (1957) Determination of glycogen. Archs Biochim. Biophys. 67, 378-386.

Peyre, A. \& Laporte, P. (1966) Effect of testosterone and estradiol on caudal epididymal sialoproteins in immature castrated rats. C. r. Séanc. Soc. Biol. 160 , 2178-2180.

Podesta, E.J. \& Rivarola, M.A. (1974) Concentration of androgens in whole testis, seminiferous tubules and interstitial tissue of rats at different stages of development. Endocrinology 95, 455-461.

Rajalakshmi, M. \& Prasad, M.R.N. (1968) Changes in the sialic acid content of the accessory glands of the male rat. J. Endocr. 41, 471-476.

Rajalakshmi, M. \& Prasad, M.R.N. (1969) Changes in sialic acid in the testis and epididymis of the rat during the onset of puberty. J. Endocr. 44, 379-385.
ReID, B.L. (1959) The structure and function of the epididymis. II. The histogenesis of the rat epididymis. Aust.J.Zool.7, 22-38.

Riar, S.S., SeTTY, B.S. \& KaR, A.B. (1973) Studies on the physiology and biochemistry of mammalian epididymis. Biochemical composition of epididymis. A comparative study. Fert. [Steril. 24, 355363.

Setchell, B.P. (1970) The secretion of fluid by the testis of rats, rams and goats with some observations on the effect of age, cryptorchidism and hypophysectomy. J. Reprod. Fert. 23, 79-85.

Sholl, S.A. \& Leathem, J.H. (1973) Effect of postnatal maturation and castration on rat epididymal carbohydrate metabolism. Proc. Soc. exp. Biol. Med. 142, 635-637.

Turner, P.C. \& Johnson, A.D. (1971) Epididymal lipid of the rat with and without testicular contribution. J. Reprod. Fert. 27, 249-255.

UMBREIT, W.W., BURRIS, R.H. \& STAUFFER, J.F. (1959) Manometric Techniques. Burgess Publishing Co., Minneapolis.

Waites, G.M.H. \& Setchell, B.P. (1969) Physiology of the testis, epididymis and scrotum. Adv. Reprod. Physiol.4, 1-63.

WhITE, I.G. (1959) Studies on the estimation of glycerol, fructose and lactic acid with particular reference to semen. Aust. J. exp. Biol. Med. 37, 441450.

Received 12 August 1976 